* Lina anea, L.-Common at Hakodaté and Yokohama.

"20-punctata, Scop.-Common in all the islands.
* „, populi, L.-
do.,
on the mountain sallow.

*Gonioctena rufipes, De G.-Hakodaté ; occurs also in America.

*Phyllotreta undulata, Steph.-Common in all the islands.

* Balanomorpha rustica, L.-A single example; Nagasaki.

Ancylopus melanocephalus, Costa-Common in all the islands.

* Coccinella 7-punctata, L.-

do.

*Chilocorus renipustulatus, Scriba-

do.

13, The Lees, Folkestone: December, 1873.

\title{
DESCRIPTIONS OF THREE NEW SPECIES OF SCARABAEIDAE FROM AUSTRALIA AND JAPAN.
}

BY CHAS. O. WATERHOUSE.

\section{Temnoplectron LeVE, $s p$. nov.}

Ovatum, convexum, nigrum, sub-piceo micans, sub-nitidum. Capite sub-plano; fronte leviter convexo subtilissime punctulato; clypeo subtiliter et crebre punctulato; margine antico in medio bidentato. Thorace subtiliter et crebre punctulato, longitudine duplo latiori, sat convexo, antice leviter angustato; margine antico emarginato, postico leviter biarcuato, lateribus ante medium subito oblique angustatis; angulis anticis rectis, posticis sub-rotundatis. Elytris convexis, lavibus, longitudine paulo latioribus, lateribus rotundatis; singulis lavissime sex-striatis, striis vix conspicuis. Ore, antennis, thorace antice subtus (utrinque excavato), pedibusque piceis.

Hab.: Queensland. Coll. Brit. Mus.

Long. $4 \frac{1}{2}$ lin., lat. $3 \frac{1}{3}$ lin.

This species may at once be distinguished from $T$. rotundatum by its rather shorter and broader form, and by the almost entire absence of striæ on the elytra.

The following species somewhat resembles Epilissus, but I think is better associated with Temnoplectron.

\section{Temnoplectron parvulum, $s p$. nov.}

Elongatum, sub-ovatum, piceum, nitidum. Capite magno, leviter convexo, subrotundato, subtilissime et crebre punctulato; margine antico depresso, in medio bidenticulato atque inter denticulos emarginato. Thorace crebre et distincte punctato, longitudine duplo latiori, sat convexo, antice angustato, margine antico leviter emarginato, postico rotundato, lateribus ad angulos anticos subito oblique angustatis; angulis anticis rectis, posticis obtusis. Elytris sat convexis, lavibus, longitudine non brevioribus; infra humeros latioribus, dein ad apicem arcuatim angustatis; singulis tenuissime septem-striatis. Tibiis compressis, arcuatis; tarsis compressis. Antennarum clava nigro-fusca.

Long. $2 \frac{1}{2}$ mill., lat. $1 \frac{1}{2}$ mill.

Hab. : S. Japan. Coll. Brit. Mus. and G. Lewis. 
The second specimen brought by Mr. Lewis only measures two millimètres in length.

\section{Menthophilus tuberculatus, $s p$. nov.}

Latus, convexus, sub-opacus, fuligineus. Capite fortiter sat dense punctato; margine antico in medio deflexo et leviter emarginato, utrinque obtuse tridenticulato; fronte leviter convexo. Thorace fortiter et sat dense punctato, punctis piliferis, et capite et longitudine sud duplo latiori, convexo, antice in medio linea longitudinali elevata nitida, posticeque utrinque tuberculis duobus nitidis; margine antico emarginato, postico fere recto (vix rotundato); lateribus paulo explanatis (marginibus serratis, piliferis, setiferis) ante medium oblique angustatis et leviter emarginatis, a medio ad angulos posticos paulo rotundato-angustatis; angulis anticis rectis, posticis retrorsis et rectis. Elytris convexis, longitudine paulo latioribus, thorace vix angustioribus, lateribus rotundatis, ad apicem deflexis; sutura costata et obsolete nodosa, nodulis punctatis; singulis septem-striatis, striis duplicibus et distanter punctatis; interstitiis sub-planis, opacis, impunctatis, $1^{\circ}, 3^{\circ}, 5^{\text {to }}$ sextoque 9-vel 11-nodulosis, nodulis parvis et fortiter punctatis, interstitiis 2 et 4 fortiter septem-nodosis, nodis postice fortiter punctatis et setiferis. Corpore subtus pedibusque quatuor posticis fortiter punctatis. Tibiis anticis ad apicem truncatis et incurvatis, extus fortiter tridentatis; posticis fere rectis.

Long. $4 \frac{1}{2}$ lin., lat. $3 \frac{1}{4}$ lin.

Hab. : "New Holland." Coll. Brit. Mus.

British Museum : November 15th, 1873.

\section{DESCRIPTION OF A SECOND SPECIES OF CATHORMIOCERUS FROM GREAT BRITAIN.}

BY E. C. RYE.

\section{Cathormiocerus maritimus (Moncreaff, MS.), sp. $n$.}

\section{(Group 1 ; Seidlitz.)}

Corpore elytrisque opaco-squamosis, thoracis basi fortius angustatâ, lateribus fortissime ante medium rotundato-ampliatis; scrobe irregulari, curvatâ, sub-foveiformi, nitidâ, oculum attingenti; elytris nigro-setosis, in nuper exclusis concinne tessellatis.

Long. $3 \frac{1}{2}-4 \mathrm{~mm}$. (lin. anglic. $\left.1 \frac{1}{2}-1 \frac{3}{4}\right)$.

§. Paulo major, scapo ad basin ipsam constricto, inde abruptim valde dilatato, oblique quasi angulatim extus curvato, angulis basalibus (scilicet supra basin constrictam) prominentibus; funiculo crassiore.

7. Antennis paulo minus incrassatis, scapo aque dilatato necnon curvato, sed angulis basalibus minus prominulis.

Habitat Angliam meridionalem, in insulâ "Portsea" sub muscis graminibusque prope salinam à Dom. Moncreaff rariùs inventus.

The characters of this insect have long ago been pointed out by me (Ent. Mo. Mag., vii, p. 150), and I now describe it, adopting the 


\section{$2 \mathrm{BHL}$ Biodiversity Heritage Library}

Waterhouse, Charles Owen. 1874. "Descriptions of three new species of Scarabaeidae from Australia and Japan." The Entomologist's monthly magazine 10, 175-176. https://doi.org/10.5962/bhl.part.4735.

View This Item Online: https://www.biodiversitylibrary.org/item/36494

DOI: https://doi.org/10.5962/bhl.part.4735

Permalink: https://www.biodiversitylibrary.org/partpdf/4735

\section{Holding Institution}

Smithsonian Libraries

\section{Sponsored by}

Smithsonian

\section{Copyright \& Reuse}

Copyright Status: NOT_IN_COPYRIGHT

This document was created from content at the Biodiversity Heritage Library, the world's largest open access digital library for biodiversity literature and archives. Visit BHL at https://www.biodiversitylibrary.org. 